\title{
Design of Experiment (DOE) Analysis with Response Surface Method (RSM) to Optimize the Electroplating Parameter
}

\author{
Adi Permana ${ }^{1 *}$, Humiras Hardi Purba², and Sawarni Hasibuan ${ }^{3}$ \\ ${ }^{1-3}$ Master of Industrial Engineering Program, Industrial Engineering Department, Universitas Mercu Buana \\ Jln. Meruya Selatan No 1, Jakarta 11650, Indonesia \\ 'adi.permana_ap@yahoo.com; ${ }^{2}$ humiras.hardi@mercubuana.ac.id; ${ }^{3}$ sawarni02@mercubuana.ac.id
}

Received: $27^{\text {th }}$ January 2021/ Revised: $30^{\text {th }}$ March 2021/ Accepted: $30^{\text {th }}$ March 2021

\begin{abstract}
How to Cite: Permana, A., Purba, H. H., \& Hasibuan, S. (2021). Design of Experiment (DOE) Analysis with Response Surface Method (RSM) to Optimize the Electroplating Parameter. ComTech: Computer, Mathematics and Engineering Applications, 12(2), 99-109. https://doi.org/10.21512/comtech.v12i2.6998
\end{abstract}

\begin{abstract}
Identifying optimum process parameters, their effects, and contributions to the outcomes of electroplating thickness in the electroplating process is very time-consuming and requires high cost. Small Medium Enterprises (SMEs) use a traditional approach in determining optimum process parameters that can lead to an inefficient result, such as a high variation in the response. Design of Experiment (DOE) can identify the significant factors in the process, show the correlation of each factor, and determine the optimum process parameter to achieve the targeted response (thickness). The research aimed to use DOE analysis with Response Surface Method (RSM) to optimize the electroplating parameter. It was experimental research using real production part as the DOE sample and Minitab statistic software to analyze the result. The used sample in the experiment was the continuous product order from a home appliance manufacturer. Then, four factors during the electroplating process were chosen: electrolyte concentration, electric current, duration of timing, and surface of the electroplated area. The results show that to reach thickness at 40 microns, it needs the optimum parameter with 5 minutes duration, electrolyte density of 22 Baume, electricity of 5 Volt, and surface area product of $415 \mathrm{~cm}^{2}$. This condition leads to capacity improvement of up to $100 \%$. Hence, it decreases overtime costs and contributes to reducing energy consumption.
\end{abstract}

Keywords: Design of Experiment (DOE), Response Surface Method (RSM), electroplating parameter

\section{INTRODUCTION}

Nowadays, with modern technology and advanced engineering science, many goods and equipment made from metal and plastic are protected by electroplating to make them last longer. In some cases, it adds aesthetic to the goods, such as in-car manufacture or home appliances. Electroplating is a process of coating a film layer with the formation of metal ions onto the goods surface through the electrochemical ionization process with electrolyte chemical and electric current (Gamburg \& Zangari, 2011). The main goal of electroplating is to protect the surface from oxidation through the use of organic layer, inorganic layer, or metal. It makes the surface of goods or equipment have a longer life (Kanani, 2004). The coating thickness depends on some factors, including the current density and time. The other factors are electrolyte solution and the surface geometric (Schlesinger \& Paunovic, 2010).

The electroplating process still has many issues, especially in the quality result that directly impacts the productivity performance. This condition leads to an increase in claims and business endanger due to low customer satisfaction. Meanwhile, the most important factor in maintaining customer satisfaction is high product quality (Hoe \& Mansori, 2018). Globally, the defect rate in the electroplating process is more than $10 \%$ (Knappich, Hoffman, Knauer, \& Patalewski, 2018). However, in some companies, it still exceeds $20 \%$. One of the main rejections is from the thickness variation. The thickness variation can be caused by various process inputs and process parameters (Aramphongphun \& Nampanya, 2016). 
Generally, traditional experiment design is applied to determine the optimum process parameter. However, it does not consider the interaction between factors that significantly impact the thickness. The companies still find many variations on the thickness, even it is only caused by little changes in the parameters. Another difficult issue is identifying optimum process parameters that somehow can cause low productivity, such as longer lead time or waiting time due to lack of information from the trial stage. Furthermore, SMEs usually neglect the advanced methods or more scientific approaches due to their lack of information and expertise in their business. At this point, proper experiment design is required to overcome the current issue in the electroplating process. The introduction of this method is required to socialize the better approach, especially in the experimental design.

Design of Experiment (DOE) is a statistical method used in experimental design in laboratory, research, and development of new product or formula. DOE is applied in many industries to determine the optimum parameter from many variables or factors to improve process yield, reduce variation, and decrease overall cost (Montgomery, 2013). DOE also allows the companies to consider many factors or variables simultaneously with a more accurate result that can lead to faster experiment than the traditional approach, such as One Factor at a Time (OFAT). Hence, it makes DOE use less cost (Roy, 2001).

DOE as a scientific experimental tool has increased significantly in the past 20 years in manufacturing and non-manufacturing industries worldwide (Durakovic, 2017). DOE successfully determines the most important factor or variable to control to achieve optimal process performance (Kazemain, Ebrahimi-Nejad, \& Jaafarian, 2018). DOE is also a powerful tool for quantitative analysis in experimental design which is employed through Central Composite Design (CCD), Response Surface Method (RSM), full factorial analysis, Taguchi design, and so on (Vahdani, Ghazavi, \& Roustaei, 2020).

Response Survey Method (RSM) is an experimental model that is mostly concerned with approximating a complex unknown function with a low-order polynomial (Anderson-Cook, Borror, \& Montgomery, 2009). RSM is a method with mathematical and statistical techniques for modeling and analyzing problems in which several variables influence the response. The objective of this method is to optimize the response or output (Montgomery, 2013). RSM becomes the most suitable method in the optimization process to predict the optimum parameters. Moreover, it can save time and minimize the experiment cost (Doniavi, Hosseini, \& Ranjbary, 2016).

In the research, the electroplating process in SMEs is selected due to the familiarization of the DOE in SMEs and insufficient resources like an expert in statistical engineering or process optimization. It is also to make sure that the SMEs can deliver a good product quality. All companies need to systematically and continuously improve the quality of existing products and processes to ensure business continuity (Damsiar, Prastyo, \& Rimawan, 2018). In the current market and complex business environment, the organization must fulfill the customers' requirements and their expectations that are critical to satisfaction, such as excellent product quality, on-time delivery, and very competitive price (Permana, Purba, \& Rizkiyah, 2021). Customer satisfaction is defined by the main factor of product and service quality (Hernadewita, Rochmad, Hendra, Hermiyetti, \& Yuliani, 2019).

However, many people believe that experimental design is too expensive to do in SMEs. It has the limitation of resources and experts. Moreover, they usually use the traditional approach (OFAT). In the end, this traditional method may not deliver an accurate result and sometimes misleads to the solution and creates wasteful, inefficient, and costly activities.

The focus of the research is to determine an optimum parameter of the electroplating process that the critical to quality is the visual appearance and thickness of the product. The research focuses on nickelchrome plating (Ni-Cr) as it is the top plating used in the SMEs compared to another alloy plating, such as zinc and hard chrome. An addition of alloy elements like chromium is considered one of the methods to increase the corrosion resistance and better protection to the surface to enhance the corrosion resistance of $\mathrm{Ni}-\mathrm{Fe}$ coating (Torabinejad, Aliofkhazraei, Assareh, Allahyarzadeh, \& Rouhaghdam, 2017).

The research focuses only on the electrolysis process and ignore other processes, including the preparation, administration, quality check, and other setup processes. The trial process employs only one person in the electrolysis process to minimize variation due to different operators (reproducibility issue). Moreover, the used chamber is the same chamber for the production purpose, including another equipment in the experiment (same process environment) to minimize trial bias due to different process environments, including man, machine, material, or method.

\section{METHODS}

The research is an experimental type in the production area with real production parts used as a sample. A DOE with RSM using CCD is applied to determine a quadratic equation pattern of the factors that will correlate during the experiment (Kazemian \& Gandjalikhan Nassab, 2020). CCD and Box Behnken Designs (BBD) are the standard response surface designs (Allen, 2019). CCD is commonly used by researchers to determine the optimum response from many factors or variables within the process (Dean, Morris, Stufken, \& Bingham, 2015).

The sampled product for the experiment is the continuous product order from a home appliance manufacturer, as shown in Figure 1. The part is the solid cylinder metal part which requires nickel-chrome protection to surround the body area with a thickness 
of a minimum of 40 microns as the customer's critical to quality. Furthermore, the electroplating process in the workshop of the SME is shown in Figure 2. The main chamber and its machine's equipment size is approximately L: $1.500 \mathrm{~mm} \times \mathrm{W}: 800 \mathrm{~mm} \times \mathrm{H}: 1.300$ $\mathrm{mm}$ with the volume of nickel chemical up to 1.500 liters.

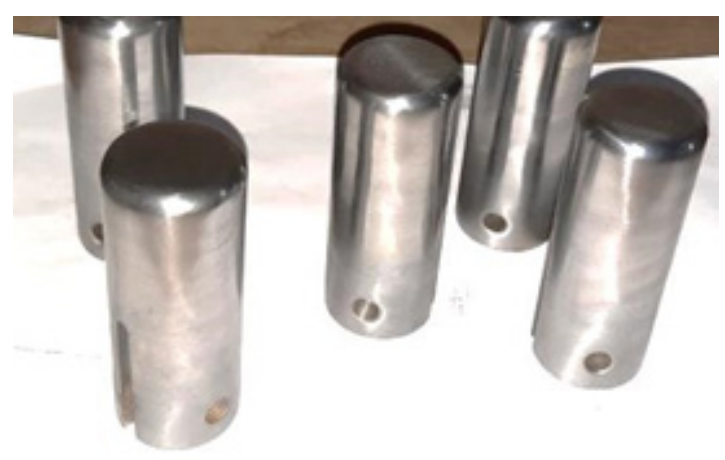

Figure 1 Sample of Cylinder Part $(\mathrm{D}=2,4 \mathrm{~cm}$ and $\mathrm{H}=10 \mathrm{~cm})$

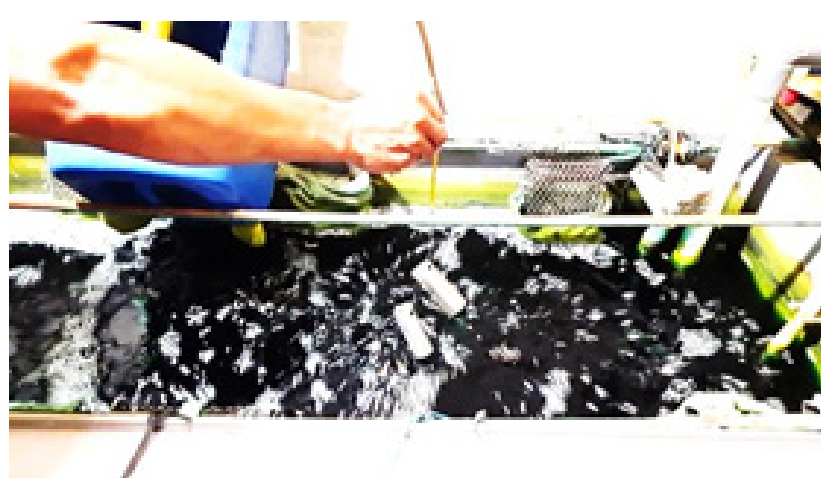

Figure 2 The Example of Electroplating

Four used factors during the electroplating process are selected: electrolyte concentration, electric current, duration of timing, and surface of the electroplated area. According to the historical data, all factors are set with high $(+1)$ and low (-1). Additional replication is not used due to limited resources and saving time and cost. The complete detail of factors and their level can be seen in Table 1 .

Table 1 Experimental Factors

\begin{tabular}{lclcc}
\hline Factors & Unit & Measurement & $\mathbf{- 1}$ & $\mathbf{+ 1}$ \\
\hline Electrolyte & & Hydrometer - & 22 & 23 \\
Current (Voltage) & Volt & Baume & 5 & 8 \\
Duration (Timing) & Minutes & Stopwatch & 10 & 30 \\
Surface area & & Caliper & 166 & 415 \\
\hline
\end{tabular}

Notes:

-1 lowest parameter

+1 highest parameter

The level in the experiment is according to the practical range of the process by considering the cost and machine capacity and capability. The lowest parameter $(-1)$ is according to the minimum current process parameter as it is also applicable to the maximum parameter or the highest parameter $(+1)$. The increase in the electrolyte will increase much cost. A similar idea is also applied to duration that it will significantly impact production capacity. Meanwhile, voltage and surface area only affect the maximum capability and capacity of the machine. All the experiments run in a real environment process to avoid bias in production if the experiment is done in a lab environment. The response of the experiment is the thickness and visual appearance of the product. However, the experimental analysis only uses the measurable response, and the thickness of nickelchrome plating is measured by the thickness gauge tester nicety (CM8806FN).

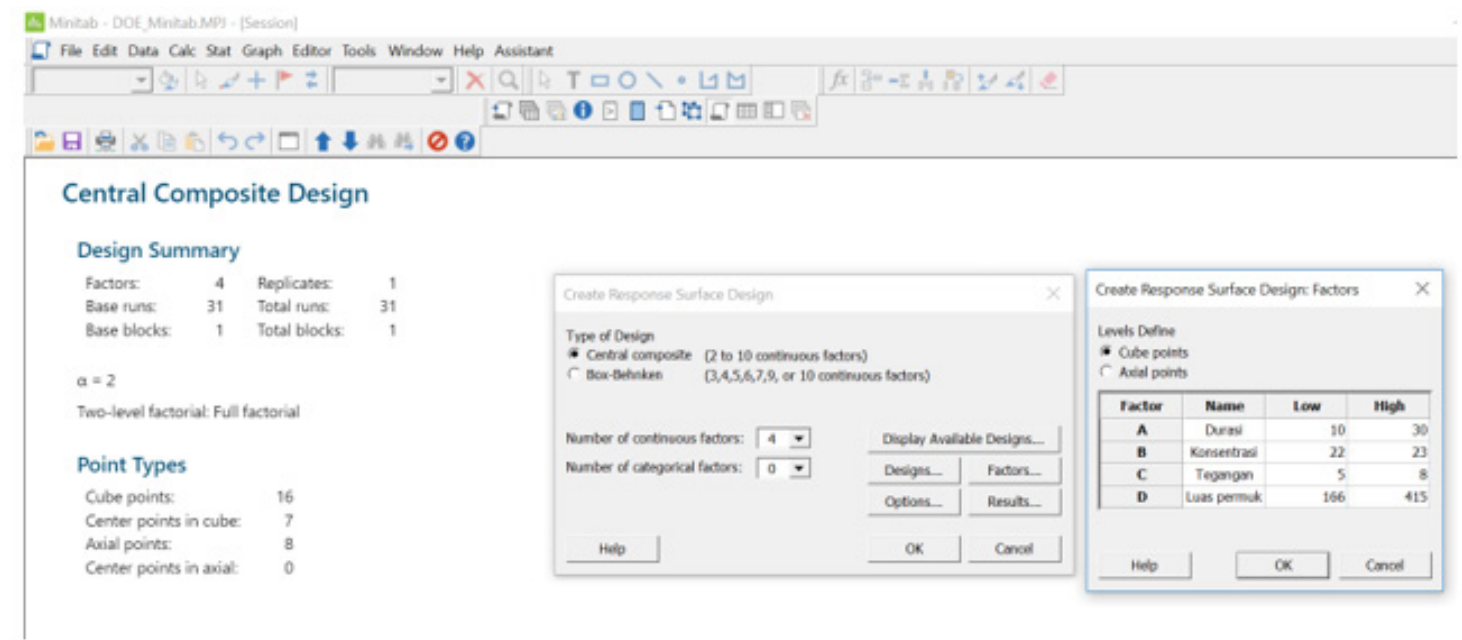

Figure 3 DOE Model with CCD 
Moreover, the software to create the experimental design is Minitab software version 18. It is widely used by statistic experts, practitioners, or engineers around the world. The designed model requires 31 runs with some replication on the center of the trial run combination. The experimental model is developed randomly through the use of that statistic software. It creates the experimental worksheet according to the factors and levels. Figure 3 shows the screen capture of the Minitab that generates the random worksheet of trial run in the experiment, as shown in Figure 4. This random worksheet aims to minimize bias during the experiment.

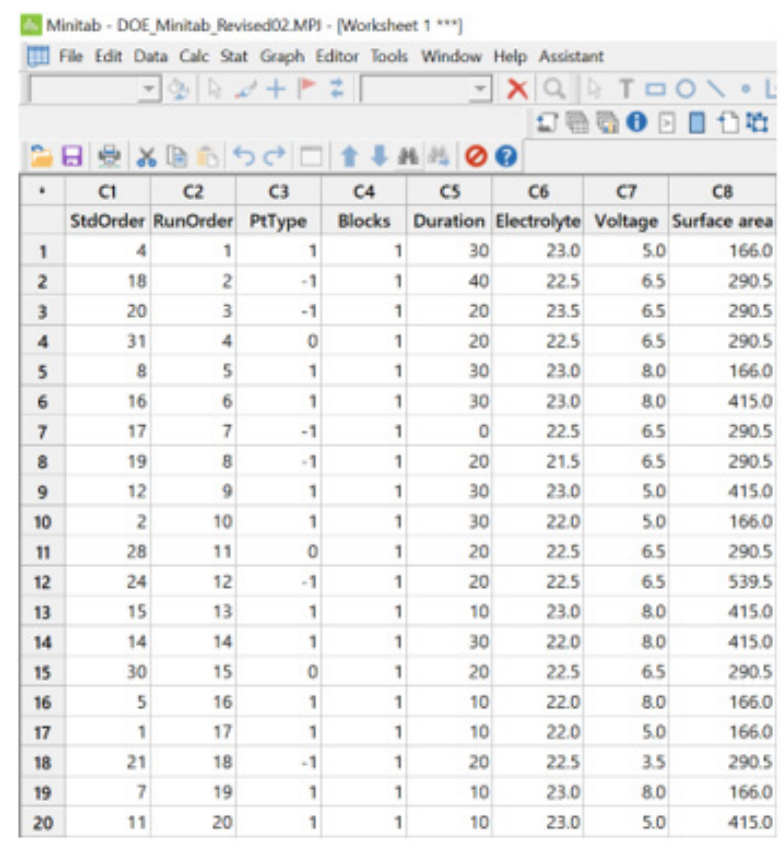

Note: $\mathrm{C} 1-\mathrm{C} 8$ is the default column numbering in the Minitab worksheet

Figure 4 Randomized Model by Minitab Software

The statistical model applies multi-regression analysis with a least-square method using Equation (1). The $Y$ is the response, and $X_{i}$ and $X_{i}$ are the normalized values of the model variables. Moreover, $\beta_{0}$ is a constant coefficient, $\beta_{i}$ is the linear coefficient, $\beta_{i j}$ is the coefficient of the interaction, and $n$ is the number of the model variables.

$$
Y=\beta_{0}+\sum_{i=1}^{n} \beta_{i} X_{i}+\sum_{i<j}^{n} \sum_{j}^{n} \beta_{i j} X_{i} X_{j}
$$

The model in Equation (1) is known as the Scheffé polynomials model. It can find the interaction between experimented factors (Vahdani et al., 2020). Moreover, the significance value of variables and their interactions will be determined by the Analysis of Variance (ANOVA). ANOVA is used to uncover the main interaction and its effects of categorical independent variables (called "factors") on an interval dependent variable (Garson, 2013). This method is the workhorse analysis of experimental designs, consisting of F-tests of main effects and the interactions (Rouder, Engelhardt, McCabe, \& Morey, 2016). ANOVA, in fact, is easily implemented in the general purpose of multiple regression procedures, even with unequal numbers of observations or trials in the various conditions (Judd, McClelland, \& Ryan, 2017). ANOVA is also a powerful method to evaluate three or more normal samples (Cruz-Huicochea \& Verma, 2013).

\section{RESULTS AND DISCUSSIONS}

The experiment data are completed from 31 trial runs with 102 samples. Statistical analysis through Minitab software is done soon after the experiment is completed, and all the responses are tabulated to the Minitab worksheet. Around 31 trial data with thickness as the response are analyzed with the digital thickness gauge tester. The results are shown in Table 2 (See Appendices).

The main effect plot in Figure 5 (see Appendices) shows the factor effect on the thickness. The first factor is duration or timing. It obviously results in the linear plot. It means the longer duration will add the thickness of the electroplating and vice versa. However, a longer duration will impact the process lead time. On the calculation, the accepted duration ranges from 5 to 10 minutes. This result is validated by other research that a quantitative analysis of nickel electroplating on the metal surface shows the increase in thickness in the linear pattern by the additional time of electrolysis duration (Wahab, Noordin, Izman, \& Kurniawan, 2013). Another previous research also shows the same phenomenon on parameter optimization of electroplating nickel chrome. It finds that duration and density significantly contribute to the electroplating thickness (Khedekar, Gosavi, Gogte, \& Brahmankar, 2017).

Next, there is an electrolyte with the nonlinear plot. The curve forms a quadratic pattern. The thickness gets thicker with 21,5 Baume and less until 23 Baume. It also increases back after 23,1 Baume. This phenomenon is interesting to explore. In a practical environment, people believe that the more number on electrolyte is, the more it will be thick and vice versa. The previous research also validates this result that the chemical electrolyte significantly affects the thickness with nonlinear pattern (Oloruntoba, Eghwubare, \& Oluwole, 2011). Another previous research also concludes that variation of the thickness on nickel electroplating is caused by the electrolyte which forms a nonlinear pattern (Jaramillo-Gutiérrez, Sierra-González, Ramírez-González, Pedraza-Rosas, \& Pedraza-Avella, 2021).

Another factor is voltage with a plate shape. It indicates the low effect on the thickness. However, the high voltage can lead to the burning defect on the surface due to an over electricity current. In normal use, the voltage is set at $5-8$ Volts. The last factor is the surface area. It also forms the plate line. It means the low effect on the thickness. 
In Figure 6 (see Appendices), the surface plot of each factor identifies the correlation of each factor. The holding value is identified at the duration of 20 minutes, electrolyte at 22,5 Baume with voltage at 6,5 Volt, and surface area at $290,5 \mathrm{~cm}^{2}$. According to the surface plot, electrolyte with voltage, surface area, and duration have a significant correlation as shown by the curve, respectively.

The contour plot in Figure 7 (see Appendices) shows significant factors of electrolyte and duration, while the holding values are voltage and surface area. The contour plot shows that the second less green color in the correlation between the electrolyte varies from 21,5 Baume to 22,0 Baume to reach the thickness 30 or 60 microns (targeted thickness is 40 microns). Moreover, according to the productivity and production output target, the optimum duration is less than 10 minutes to accommodate the process lead time.

The response optimizer in Figure 8 (see Appendices) shows that the thickness target of 40 microns can be achieved only at 5 minutes duration with electrolyte at 22 Baume. The voltage is set at 5 Volt since it has a potential burning defect if it runs more than 8 Volt. Moreover, the surface area has less effect on the thickness, so it can be set at the maximum condition to increase productivity.

The ANOVA test result in Figure 9 (see Appendices) indicates only one factor with a significant effect on the thickness, which is electrolyte (p-value of 0,000$)$. Meanwhile, the duration is also close to the significant effect ( $\mathrm{p}$-value of 0,077). The other two factors (voltage and surface area) do not show a significant result with p-value 0,670 and 0,954 , respectively.

The validation result is completed to test whether the optimum parameter from the optimizer model is valid or not. Then, the research performs one sample of t-test to measure whether the resulted thickness hits the target of 40 microns or not. Around 10 samples are tested with 5 trial runs $(2$ samples for each run). The result is shown in Table 3.

Table 3 shows the result of validation from 5 batches ( 2 samples per batch). The process parameters are set as the optimum parameter that is determined from the experiment result. The duration is set at 5 minutes as this condition will increase productivity due to a shorter process lead time. Moreover, the voltage is set at 5 Volts to minimize the potential burning defect by over electric current. The electrolyte is kept at 22 Baume. Because the surface area is not a significant factor, it can be put at maximum capacity at 5 samples $\left(415 \mathrm{~cm}^{2}\right)$. This validation test runs only 2 samples $\left(166 \mathrm{~cm}^{2}\right)$ to reduce the sample number in the trial. The further analysis (hypothesis test) tests whether the result matches the targeted thickness or not.

The probability plot of the validation result for 5 minutes duration is shown in Figure 10 (see Appendices). It indicates the thickness at 39,44 microns with a standard deviation of 2,392 microns. The one sample in the t-test (see Figure 11 in Appendices) ends up with the p-value at 0,478 . It implies that the thickness hits the target of 40 microns.

The experiment result indicates that two factors significantly affect thickness (duration and the electrolyte (chemical density)). This condition is proven by the historical experience from the worker that duration and electrolyte are very critical on the thickness. It is also stated by the previous research on nickel plating electrodeposition by clearly mentioning that duration increases the add-on weight (nickel thickness) and percentage gradually (Babu, Ariharashudan, Chandrasekaran, \& Arunraj, 2018). Another previous research related to the quantitative analysis of nickel coating electrolysis on hard metal shows that increasing metal deposition rate or thicker coating within a certain time is linear (Wahab et al., 2013). Moreover, another previous research also validates this finding that an increase in duration time progresses generates an increase in the quantity of nickel deposited or the thickness (Jaramillo-Gutiérrez et al., 2021). This finding also agrees with Faraday's law in which the deposition rate is proportional to the plating current and time (Survila, 2015).

Another factor with a significant effect on the thickness is electrolyte or chemical density. The ANOVA test indicates that electrolyte has a significant effect on thickness. This result is validated by previous research in optimizing the parameters of nickelchromium electroplating. Time and density affect the thickness significantly (Khedekar et al., 2017).

Table 3 Validation Result (5 Minutes Duration)

\begin{tabular}{cccccc}
\hline $\begin{array}{c}\text { Duration } \\
(\mathbf{m i n})\end{array}$ & $\begin{array}{c}\text { Electrolyte } \\
\text { (Baume) }\end{array}$ & $\begin{array}{c}\text { Voltage } \\
(\mathbf{V})\end{array}$ & $\begin{array}{c}\text { Surface area* } \\
\left(\mathbf{c m}^{2}\right)\end{array}$ & Sample & $\begin{array}{c}\text { Thickness } \\
(\text { microns) }\end{array}$ \\
\hline 5 & 22 & 5 & 166 & 2 & 40,8 \\
5 & 22 & 5 & 166 & 2 & 36,7 \\
5 & 22 & 5 & 166 & 2 & 41,5 \\
5 & 22 & 5 & 166 & 2 & 40,0 \\
5 & 22 & 5 & 166 & 2 & 38,2 \\
\hline
\end{tabular}

*Surface area is set at $166 \mathrm{~cm}^{2}$ since it only requires two samples as it does not significantly affect the thickness according to the experiment result 
Another previous research also mentions that the higher bulk of electrolyte concentration will result in higher deposition (Kamaraj \& Sundaram, 2018). The interesting result of this electrolyte plot is the nonlinear plot. It shows a quadratic model that in certain low density at 21,5 Baume, the thickness is thicker and decreases in some increasing density. Meanwhile, it gets thicker when the density rises back to 23 Baume onward. This condition is very similar to previous research finding that the plot of the thickness $(\mu \mathrm{m})$ of nickel deposited against varying composition density forms a nonlinear plot (Oloruntoba et al., 2011). Another similar result shows that nickel concentration varies, and the variables of time and potency are not equal. So, it creates a nonlinear plot (JaramilloGutiérrez et al., 2021).

\section{CONCLUSIONS}

The research is completed with a deep analysis of the experiment result. It creates a new way and mindset of determining the optimum parameter on the electroplating process to be more beneficial and robust. As the DOE method is successfully implemented, the optimum parameter is obtained to achieve thickness at a minimum of 40 microns according to the customers' specifications. The electroplating parameter must be set with the following results: 5 minutes as the duration, the electrolyte density at 22 Baume, the electricity at 5 Volt, the surface area at a maximum capacity of $415 \mathrm{~cm}^{2}$. These parameters will enable the production capacity to increase almost double-digit since the historical duration ranges from 8 to 10 minutes for each batch. Furthermore, this improvement in the parameter can successfully reduce overtime cost and energy consumption.

In regard to the experiment results, including the use of experimental design replacing the traditional trial of OFAT, DOE is recommended to be applied. It can determine the optimum variable from many factors, especially in complex processes or environments requiring advanced tools to identify the significant factor. More importantly, it can determine the interaction between the factors that are definitely hard to observe in the traditional experiment.

The research is limited to only using one part number. So, it is only valid for this part and cannot generate common result to other part numbers. Then, some variation in the experiment time schedule follows the production schedule. It can lead to some variation in the experiment result with different environment from one trial run to other trial runs.

Future research is still required to optimize the electrolyte composition consisting of Nickel-metal solution, acid solution, buffer solution, and other chemical reagents. Additional parameter related to the chemical composition is required to determine specific formula on the electrolyte solution. Moreover, future research can try to implement a simpler experiment model to reduce the trial run. It is necessary since the current experiment requires 31 runs with almost 100 samples, which are still too many for SMEs. Considering the appropriate cost of the experimental or trial run on how the data are collected and analyzed and building protection when things may go wrong are also the important aspects that should be looked too.

\section{ACKNOWLEDGEMENT}

The research has been conducted with financial support from Universitas Mercu Buana, Jakarta, Indonesia. It supports the researchers, students, and lecturers in continuing the contribution in innovative research-thinking activities.

\section{REFERENCES}

Allen, T. T. (2019). Introduction to engineering statistics and lean six sigma: Statistical quality control and design of experiments and systems ( $3{ }^{\text {rd }}$ ed.). Springer Science \& Business Media.

Anderson-Cook, C. M., Borror, C. M., \& Montgomery, D. C. (2009). Response surface design evaluation and comparison. Journal of Statistical Planning and Inference, 139(2), 629-641. https://doi.org/10.1016/j. jspi.2008.04.004

Aramphongphun, C., \& Nampanya, C. (2016). A study of the effect of gold thickness distribution in the jet plating process to optimize gold usage and plating voltage using design of experiments. In MATEC Web of Conferences. https://doi.org/10.1051/ matecconf/20166703037

Babu, V. R., Ariharashudan, Chandrasekaran, \& Arunraj, A. (2018). Investigating of electroless nickel plating process for polypropylene nonwoven fabric. International Journal of Innovative Technology and Exploring Engineering (IJITEE), 8(2S2), 363-367.

Cruz-Huicochea, R., \& Verma, S. (2013). New critical values for $\mathrm{F}$ and their use in the ANOVA and Fisher's F tests for evaluating geochemical reference material granite G-2 (U.S.A.) and igneous rocks from the Eastern Alkaline Province (Mexico). Journal of Iberian Geology, 39(1), 13-30. https:// doi.org/10.5209/rev_JIGE.2013.v39.n1.41746

Damsiar, Prastyo, Y., \& Rimawan, E. (2018). Reduce reject painting process using six sigma method with DMAIC approach and experiments on brake disc products (1 Rc Hub) (Case study in Pt. Xyz). International Journal of Innovative Science and Research Technology, 3(10), 327-337.

Dean, A., Morris, M., Stufken, J., \& Bingham, D. (Eds.). (2015). Handbook of design and analysis of experiments. CRC Press.

Doniavi, A., Hosseini, A., \& Ranjbary, G. (2016). Prediction and optimization of mechanical properties of St52 in gas metal arc weld using response surface methodology and ANOVA. International Journal of Engineering (IJE), TRANSACTIONS C: Aspects, 29(9), 1307-1313. 
Durakovic, B. (2017). Design of experiments application, concepts, examples: State of the art. Periodicals of Engineering and Natural Sciences, 5(3), 421-439. https://doi.org/10.21533/pen.v5i3.145

Gamburg, Y. D., \& Zangari, G. (2011). Theory and practice of metal electrodeposition. Springer Science \& Business Media.

Garson, G. D. (2013). GLM univariate, ANOVA, and ANCOVA. Statistical Associates Publishing.

Hernadewita, Rochmad, I., Hendra, Hermiyetti, \& Yuliani, E. N. S. (2019). An analysis of implementation of Taguchi method to improve production of pulp on hydrapulper milling. International Journal of Production Management and Engineering, 7(2), 125-131. https://doi.org/10.4995/ijpme.2019.10163

Hoe, L. C., \& Mansori, S. (2018). The effects of product quality on customer satisfaction and loyalty: Evidence from Malaysian engineering industry. International Journal of Industrial Marketing, 3(1), 20-34. https://doi.org/10.5296/ijim.v3i1.13959

Jaramillo-Gutiérrez, M. I., Sierra-González, S. M., RamírezGonzález, C. A., Pedraza-Rosas, J. E., \& PedrazaAvella, J. A. (2021). Effect of electrodeposition parameters and surface pretreatment on the electrochemical hydrogen production using nickelplated stainless steel electrodes. International Journal of Hydrogen Energy, 46(11), 7667-7675. https://doi.org/10.1016/j.ijhydene.2019.09.205

Judd, C. M., McClelland, G. H., \& Ryan, C. S. (2017). Data analysis: A model comparison approach to regression, ANOVA, and beyond. Routledge.

Kamaraj,A. B., \& Sundaram, M. (2018). A study on the effect of inter-electrode gap and pulse voltage on current density in electrochemical additive manufacturing. Journal of Applied Electrochemistry, 48, 463-469. https://doi.org/10.1007/s10800-018-1177-3

Kanani, N. (2004). Electroplating: Basic principles, processes and practice. Elsevier.

Kazemain, M., Ebrahimi-Nejad, S., \& Jaafarian, M. (2018). Experimental investigation of energy consumption and performance of reverse osmosis desalination using design of experiments method. International Journal of Engineering (IJE), TRANSACTIONS A: Basics, 31(1), 79-87.

Kazemian, M. E., \& Gandjalikhan Nassab, S. A. (2020). Thermodynamic analysis and statistical investigation of effective parameters for gas turbine cycle using the response surface methodology. International Journal of Engineering (IJE), TRANSACTIONS B: Applications, 33(5), 894-905. https://doi. org/10.5829/IJE.2020.33.05B.22
Khedekar, D., Gosavi, V., Gogte, C., \& Brahmankar, P. (2017). Optimization of process parameters of nickel - Chromium electroplating for thickness variation using genetic algorithm. Advances in Intelligent Systems Research, 137, 41-47. https://doi. org/10.2991/iccasp-16.2017.7

Knappich, F., Hoffman, L., Knauer, D., \& Patalewski, R. (2018). New process for complete materialsroute recycling of electroplating waste. Retrieved from https://www.recovery-worldwide.com/en/ artikel/new-process-for-complete-materials-routerecycling-of-electroplating-waste_3158892.html

Montgomery, D. C. (2013). Design and analysis of experiments. John Wiley \& Sons.

Oloruntoba, D., Eghwubare, O., \& Oluwole, O. (2011). Effect of some process variables on nickel electroplating of low carbon steel. Leonardo Electronic Journal of Practices and Technologies, (18), 79-94.

Permana, A., Purba, H. H., \& Rizkiyah, N. D. (2021). A systematic literature review of Total Quality Management (TQM) implementation in the organization. International Journal of Production Management and Engineering, 9(1), 25-36. https:// doi.org/10.4995/ijpme.2021.13765

Rouder, J. N., Engelhardt, C. R., McCabe, S., \& Morey, R. D. (2016). Model comparison in ANOVA. Psychonomic Bulletin \& Review, 23, 1779-1786. https://doi.org/10.3758/s13423-016-1026-5

Roy, R. K. (2001). Design of experiments using the Taguchi approach: 16 steps to product and process improvement. John Wiley \& Sons.

Schlesinger, M., \& Paunovic, M. (Eds). (2010). Modern electroplating. John Wiley \& Sons, Inc.

Survila, A. (2015). Electrochemistry of metal complexes: Applications from electroplating to oxide layer formation. John Wiley \& Sons.

Torabinejad, V., Aliofkhazraei, M., Assareh, S., Allahyarzadeh, M. H., \& Rouhaghdam, A. S. (2017). Electrodeposition of Ni-Fe alloys, composites, and nano coatings-A review. Journal of Alloys and Compounds, 691, 841-859. https://doi.org/10.1016/j. jallcom.2016.08.329

Vahdani, M., Ghazavi, M., \& Roustaei, M. (2020). Prediction of mechanical properties of frozen soils using response surface method: An optimization approach. International Journal of Engineering (IJE), TRANSACTIONS A: Basics, 33(10), 18261841. https://dx.doi.org/10.5829/ije.2020.33.10a.02

Wahab, H. A., Noordin, M. Y., Izman, S., \& Kurniawan, D. (2013). Quantitative analysis of electroplated nickel coating on hard metal. The Scientific World Journal, 2013, 1-6. https://doi.org/10.1155/2013/631936 
Table 2 Experiment Result of DOE

\begin{tabular}{|c|c|c|c|c|c|}
\hline Run order & Duration & Electrolyte & Electricity & Surface area & Thickness \\
\hline 1 & 30 & 23 & 5 & 166 & 27,6 \\
\hline 2 & 40 & 22,5 & 6,5 & 290,5 & 28,9 \\
\hline 3 & 20 & 23,5 & 6,5 & 290,5 & 32,8 \\
\hline 4 & 20 & 22,5 & 6,5 & 290,5 & 33,7 \\
\hline 5 & 30 & 23 & 8 & 166 & 27,0 \\
\hline 6 & 30 & 23 & 8 & 415 & 29,3 \\
\hline 7 & 0 & 22,5 & 6,5 & 290,5 & 0,0 \\
\hline 8 & 20 & 21,5 & 6,5 & 290,5 & 93,8 \\
\hline 9 & 30 & 23 & 5 & 415 & 28,7 \\
\hline 10 & 30 & 22 & 5 & 166 & 85,7 \\
\hline 11 & 20 & 22,5 & 6,5 & 290,5 & 38,9 \\
\hline 12 & 20 & 22,5 & 6,5 & 539,5 & 19,7 \\
\hline 13 & 10 & 23 & 8 & 415 & 28,3 \\
\hline 14 & 30 & 22 & 8 & 415 & 102,1 \\
\hline 15 & 20 & 22,5 & 6,5 & 290,5 & 27,5 \\
\hline 16 & 10 & 22 & 8 & 166 & 32,6 \\
\hline 17 & 10 & 22 & 5 & 166 & 92,5 \\
\hline 18 & 20 & 22,5 & 3,5 & 290,5 & 21,0 \\
\hline 19 & 10 & 23 & 8 & 166 & 28,6 \\
\hline 20 & 10 & 23 & 5 & 415 & 24,4 \\
\hline 21 & 30 & 22 & 5 & 415 & 86,8 \\
\hline 22 & 20 & 22,5 & 6,5 & 41,5 & 22,9 \\
\hline 23 & 30 & 22 & 8 & 166 & 105,9 \\
\hline 24 & 20 & 22,5 & 9,5 & 290,5 & 21,8 \\
\hline 25 & 10 & 22 & 8 & 415 & 94,5 \\
\hline 26 & 20 & 22,5 & 6,5 & 290,5 & 25,3 \\
\hline 27 & 10 & 23 & 5 & 166 & 27,3 \\
\hline 28 & 20 & 22,5 & 6,5 & 290,5 & 26,7 \\
\hline 29 & 20 & 22,5 & 6,5 & 290,5 & 23,5 \\
\hline 30 & 10 & 22 & 5 & 415 & 33,6 \\
\hline 31 & 20 & 22,5 & 6,5 & 290,5 & 19,5 \\
\hline
\end{tabular}

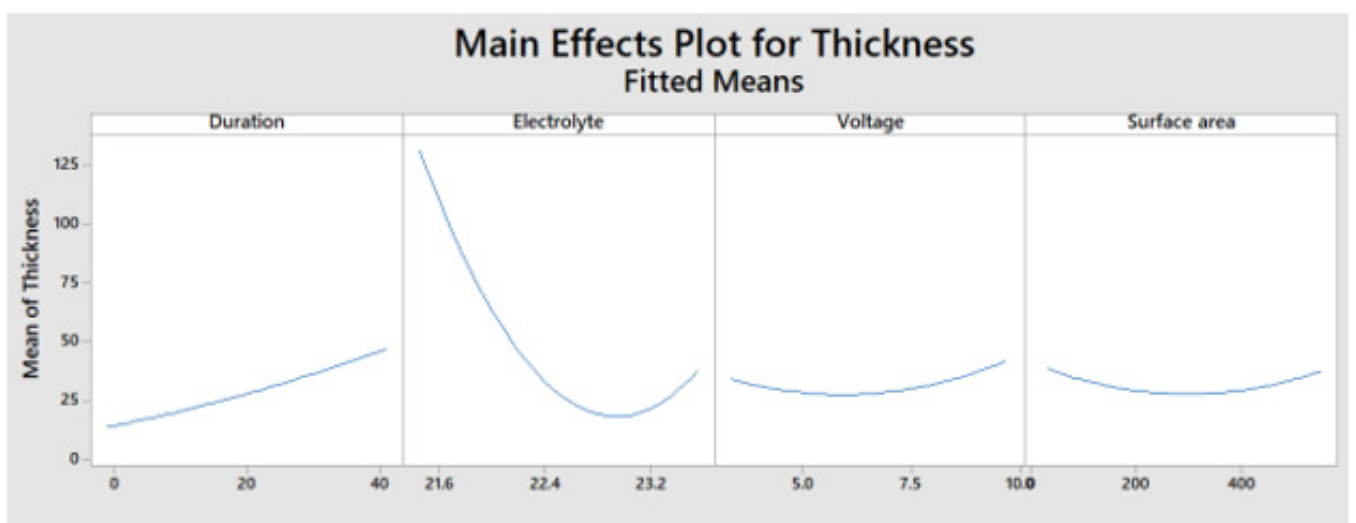

Figure 5 Plot Graph of the Main Effect in the Experiment Result 


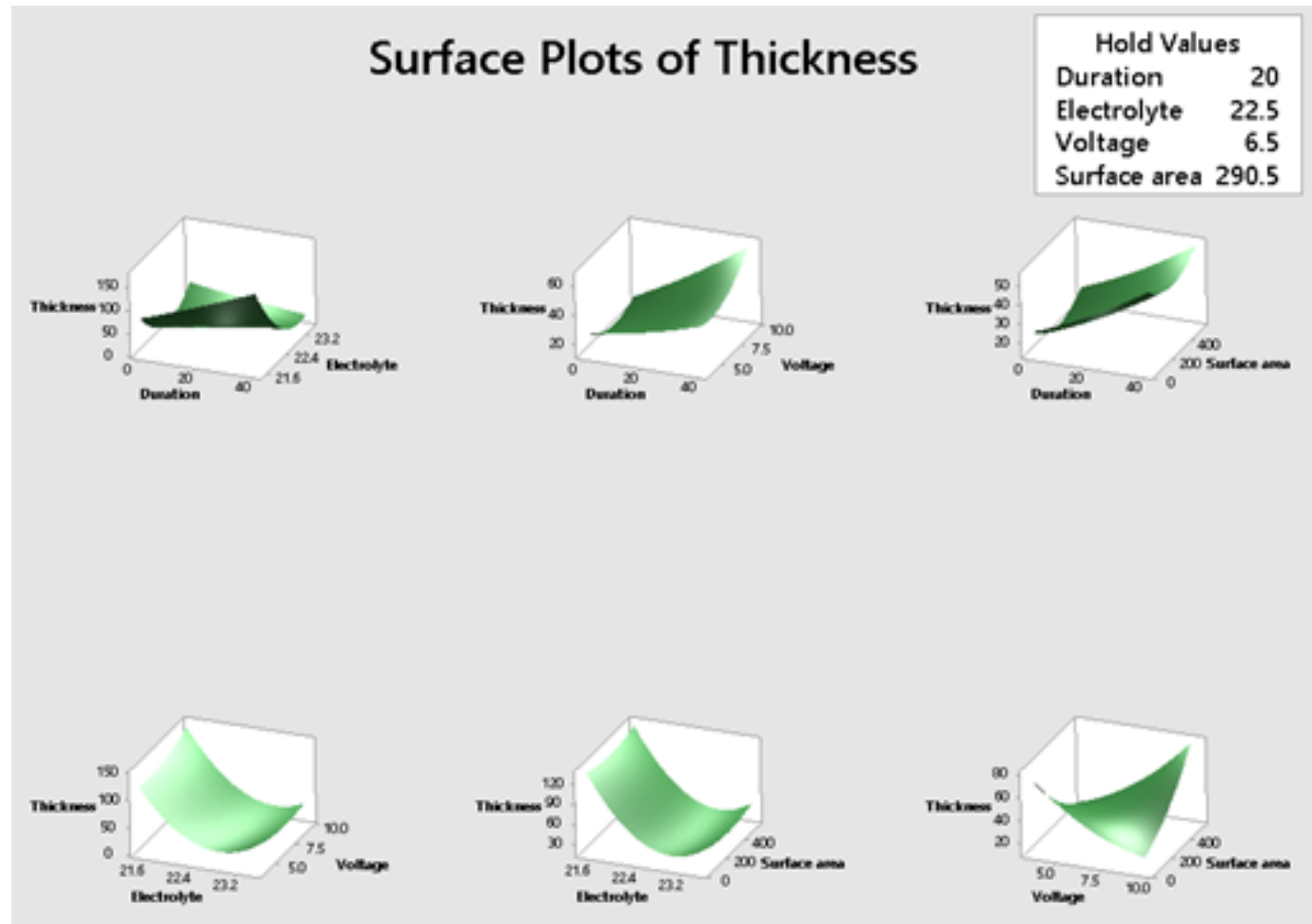

Figure 6 Surface Plot Graphs and the Correlation of the Factors

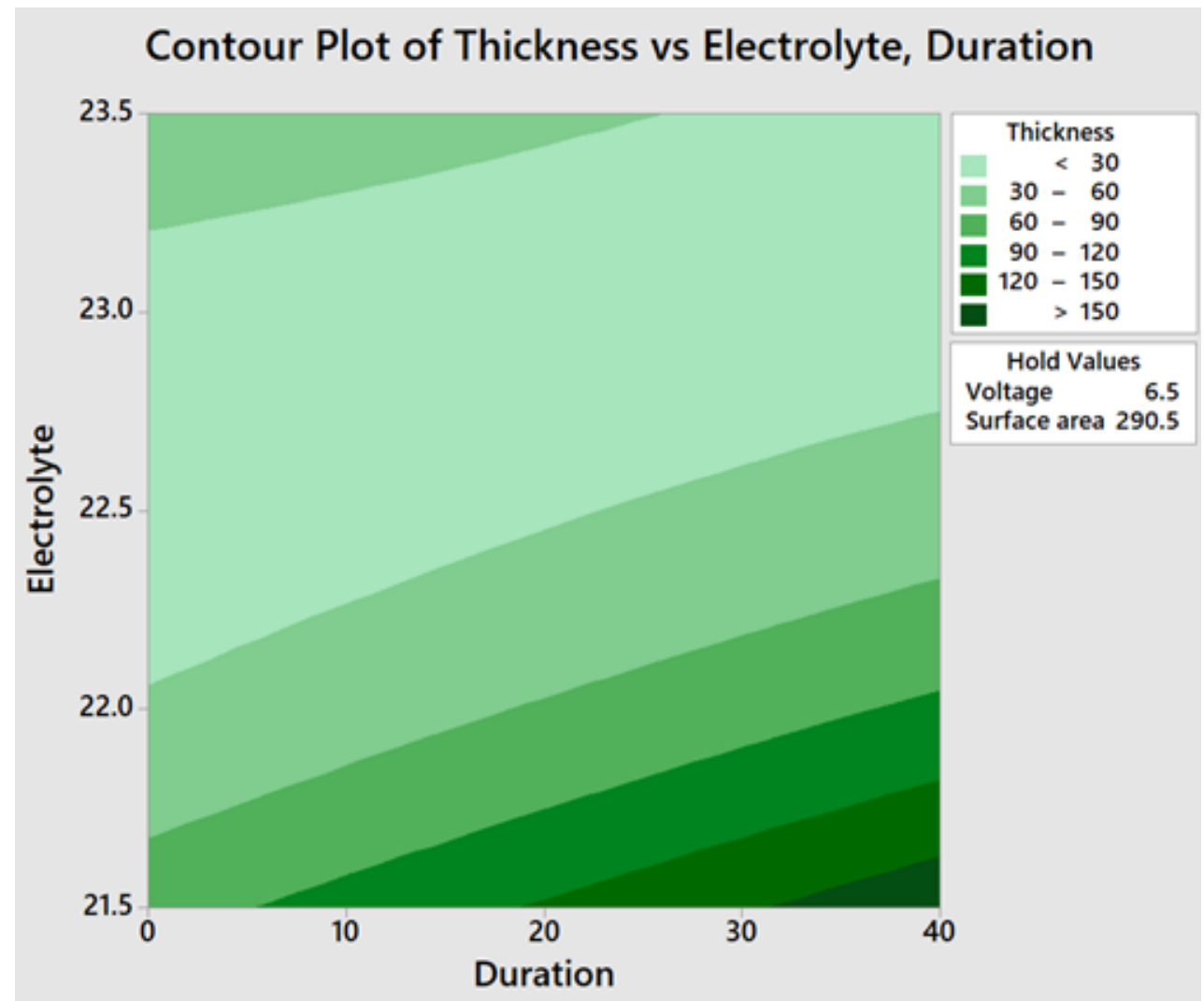

Figure 7 Contour Plots of Experimented Factors 


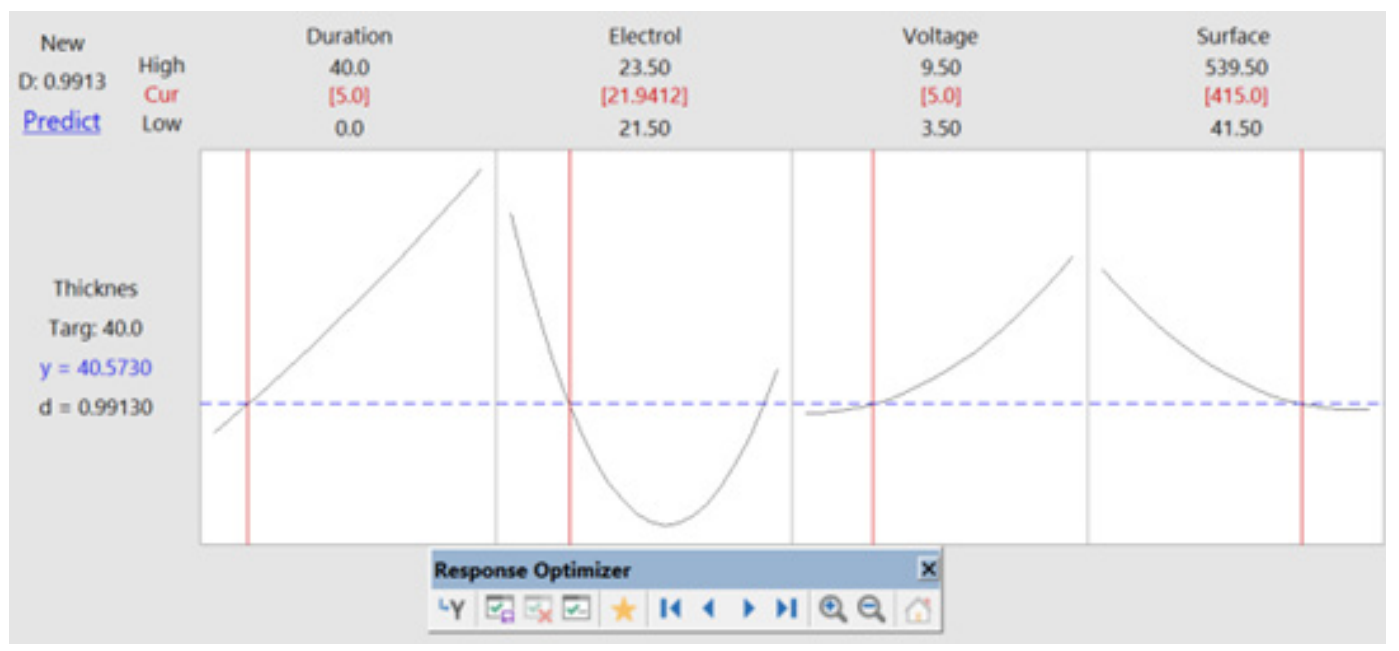

Figure 8 The Response Optimizer Plot

Analysis of Variance

\begin{tabular}{lrrrrr} 
Source & DF & Adj SS & Adj MS & F-Value & P-Value \\
\hline Model & 14 & 20141.8 & 1438.7 & 3.46 & 0.010 \\
Linear & 4 & 13461.3 & 3365.3 & 8.09 & 0.001 \\
Duration & 1 & 1489.5 & 1489.5 & 3.58 & 0.077 \\
Electrolyte & 1 & 11891.7 & 11891.7 & 28.57 & 0.000 \\
Voltage & 1 & 78.7 & 78.7 & 0.19 & 0.670 \\
Surface area & 1 & 1.4 & 1.4 & 0.00 & 0.954 \\
Square & 4 & 4714.8 & 1178.7 & 2.83 & 0.060 \\
Duration"Duration & 1 & 8.3 & 8.3 & 0.02 & 0.889 \\
Electrolyte*Electrolyte & 1 & 4643.9 & 4643.9 & 11.16 & 0.004 \\
Voltage*Voltage & 1 & 147.3 & 147.3 & 0.35 & 0.560 \\
Surface area*Surface area & 1 & 144.6 & 144.6 & 0.35 & 0.564 \\
2-Way Interaction & 6 & 1965.7 & 327.6 & 0.79 & 0.593 \\
Duration"Electrolyte & 1 & 951.9 & 951.9 & 2.29 & 0.150 \\
Duration"Voltage & 1 & 53.6 & 53.6 & 0.13 & 0.724 \\
Duration"Surface area & 1 & 0.0 & 0.0 & 0.00 & 0.992 \\
Electrolyte"Voltage & 1 & 61.5 & 61.5 & 0.15 & 0.706 \\
Electrolyte*Surface area & 1 & 0.0 & 0.0 & 0.00 & 0.998 \\
Voltage*Surface area & 1 & 898.7 & 898.7 & 2.16 & 0.161 \\
Error & 16 & 6659.6 & 416.2 & & \\
Lack-of-Fit & 10 & 6406.2 & 640.6 & 15.17 & 0.002 \\
Pure Error & 6 & 253.4 & 42.2 & & \\
Total & 30 & 26801.4 & & &
\end{tabular}

Figure 9 Analysis of Variance (ANOVA) Results

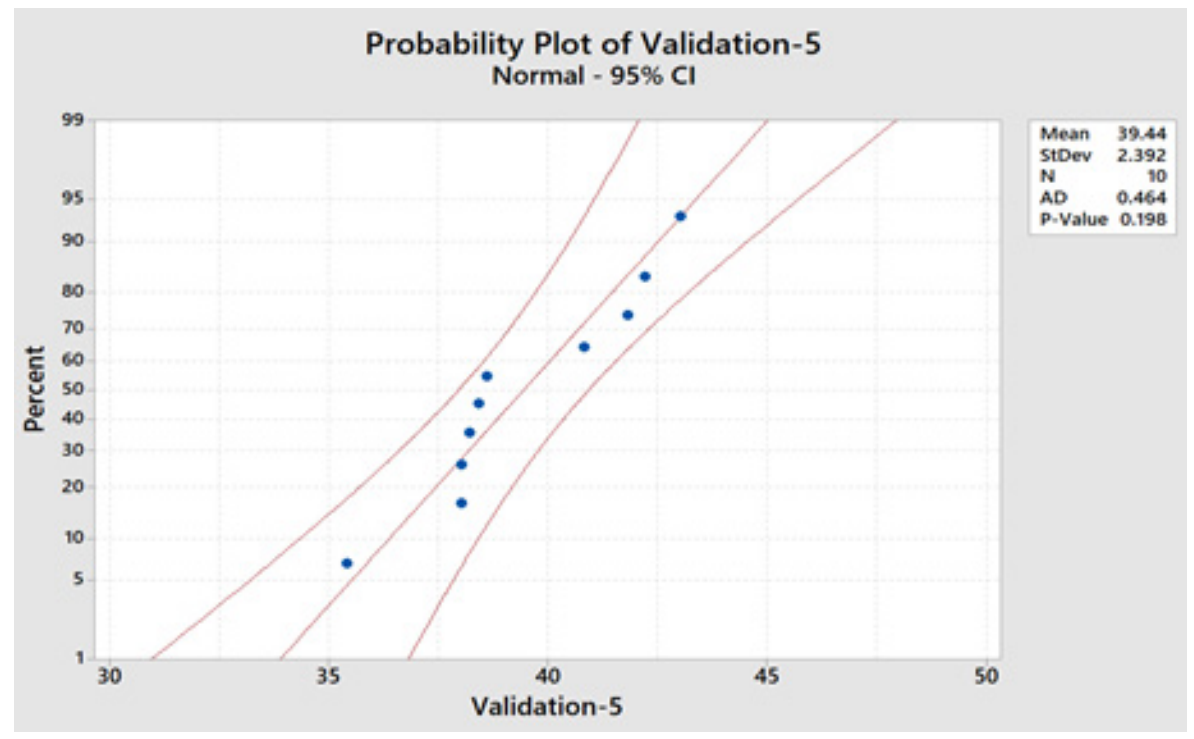

Figure 10 Probability Plot of Validation-5 Minutes 


\section{One-Sample T: Validation-5}

Descriptive Statistics

\begin{tabular}{|c|c|c|c|c|}
\hline $\mathrm{N}$ & Mean & StDev & SE Mean & $95 \% \mathrm{Cl}$ for $\mu$ \\
\hline 10 & 39.440 & 2.392 & 0.756 & $(37.729,41.151)$ \\
\hline \multicolumn{5}{|c|}{ H: mean of Validation-5 } \\
\hline \multicolumn{5}{|c|}{ Test } \\
\hline \multirow{2}{*}{\multicolumn{3}{|c|}{$\begin{array}{l}\text { Null hypothesis } \\
\text { Alternative hypothesis }\end{array}$}} & $H_{0}: \mu=$ & 40 \\
\hline & & & $\mathrm{H}_{1}: \mu \neq$ & 40 \\
\hline \multicolumn{3}{|c|}{ T-Value P-Value } & & \\
\hline & .74 & .478 & & \\
\hline
\end{tabular}

Figure 11 T-Test of Validation-5 Minutes 